\title{
Studies on Structural, Dielectric, and Electrical Properties of a $\mathrm{Ni}_{0.284} \mathrm{Zn}_{0.549} \mathrm{Cu}_{0.183} \mathrm{Fe}_{1.984} \mathrm{O}_{4}$ Piezomagnetic Material
}

\author{
R. Balusamy ${ }^{a}$, P. Kumaravel ${ }^{b}$, N. Kanagathara ${ }^{c, *}$, R. Gowri Shankar RaO ${ }^{d}$ \\ AND N.G. RENGANATHAN ${ }^{d}$ \\ ${ }^{a}$ Department of Mechanical Engineering, Al-Ameen Engineering College, Erode, India \\ ${ }^{b}$ Department of Mechanical Engineering, Institute of Road and Transport Technology, Erode, India \\ ${ }^{c}$ Jaya Engineering College, Thiruninravur, Chennai-602 024, India \\ ${ }^{d}$ School of Basic Sciences, Vel Tech University, Chennai-62, India
}

(Received July 16, 2015; revised version May 27, 2016; in final form June 17, 2016)

\begin{abstract}
Piezomagnetic materials in composition $\mathrm{Ni}_{0.284} \mathrm{Zn}_{0.549} \mathrm{Cu}_{0.183} \mathrm{Fe}_{1.984} \mathrm{O}_{4}$ were prepared by mixed oxide method at $1100^{\circ} \mathrm{C}$. Powder X-ray diffraction studies confirm the crystalline nature of the synthesized $\mathrm{Ni}_{0.284} \mathrm{Zn}_{0.549} \mathrm{Cu}_{0.183} \mathrm{Fe}_{1.984} \mathrm{O}_{4}$ piezomagnetic material. The crystallite size is calculated to be $19.332 \mu \mathrm{m}$ using the Debye-Scherrer formula. The surface morphology and particle size of the samples has been studied by scanning electron microscopy. The thermal stability and decomposition behaviour of $\mathrm{Ni}_{0.284} \mathrm{Zn}_{0.549} \mathrm{Cu}_{0.183} \mathrm{Fe}_{1.984} \mathrm{O}_{4}$ piezomagnetic material have been studied by thermogravimetric analysis at a heating rate of $15^{\circ} \mathrm{C} / \mathrm{min}$. The effective activation energy of the prepared composite was calculated using single heating rate methods: Broido's and Coats-Redfern methods. Dielectric properties of $\mathrm{Ni}_{0.284} \mathrm{Zn}_{0.549} \mathrm{Cu}_{0.183} \mathrm{Fe}_{1.984} \mathrm{O}_{4}$ piezomagnetic material have been studied in a wide range of frequencies and temperatures. The magnetic behavior of $\mathrm{Ni}_{0.284} \mathrm{Zn}_{0.549} \mathrm{Cu}_{0.183}$ $\mathrm{Fe}_{1.984} \mathrm{O}_{4}$ piezomagnetic material at room temperature has been confirmed by vibrational sample magnetometer studies.
\end{abstract}

DOI: 10.12693/APhysPolA.130.751

PACS/topics: 75.80.+q, 77.22.-d, 77.22.Gm, 68.37.Hk

\section{Introduction}

Recently piezoelectric and piezomagnetic composites are developed for various applications in the engineering fields including sensors and actuators etc. due to its interesting magnetoelectric coupling effect [1-6]. Piezomagnetic materials (PMT) have been considered to be a good candidate for acoustic-related industrial applications as well as transducers for ultrasound imaging systems in medical industry applications. Multifunctional electronic materials and integrated intelligent devices will be of great significance for acoustics, information engineering and are needed in the development of advanced technologies, especially mechano-electronic integrative units. These materials have extensive application in the vibration, survey and control fields because of their higher electromechanical conversion efficiency, big stress, high energy density and rapid mechanical response due to its piezomagnetic effect $[7,8]$. The processing and magnetoelectric coupling effect of those composites have been studied by Nan [9]. The theoretical basement for the dynamic control of the piezoelectric, piezomagnetic materials in the space spherical symmetry has been discussed by Qun Guan [10].

Magnetic antiperovskites show a variety of magnetic orderings and phase transitions. These materials exhibit superconductivity with critical temperature

\footnotetext{
*corresponding author; e-mail: kanagathaara@gmail.com
}

of $8 \mathrm{~K}\left(\mathrm{Ni}_{3} \mathrm{MgC}\right)$ and a giant magnetoresistance of more than $10 \%$ in pulsed magnetic fields $\left(\mathrm{Mn}_{3} \mathrm{GaC}\right)$ [11]. Kamishima et al. tried to fabricate heterostructures formed by piezoelectric materials and magnetic antiperovskites as magnetoelectric materials [12] and showed that the magnetic structure of antiperovskite, such as $\mathrm{Mn}_{3} \mathrm{GaN}$, can be controlled by a small applied biaxial strain [13]. The nonlinear magnetoelectric coefficient greatly depends on piezomagnetic strain coefficient which could be increased by increasing the Metglas $/ \mathrm{Pb}\left(\mathrm{Mg}_{1 / 3} \mathrm{Nb}_{2 / 3}\right) \mathrm{O}_{3}-\mathrm{PbTiO}_{3}$ length due to magnetic flux concentration. Such materials find its applicability in sensor field that requires no dc bias [14] and the numerical solution for a three-layered magnetoelectroelastic strip made of piezoelectric $\mathrm{BaTiO}_{3}$ and piezomagnetic $\mathrm{CoFe}_{2} \mathrm{O}_{4}$ materials [15]. Two comprehensive micromechanical models for the analysis of piezomagneto-thermoelastic smart composite structures are developed and their practical importances are reported by Hadjiloizi et al. [16].

In the present work, we are reporting the synthesis of $\mathrm{Ni}_{0.284} \mathrm{Zn}_{0.549} \mathrm{Cu}_{0.183} \mathrm{Fe}_{1.984} \mathrm{O}_{4}$ piezomagnetic material by mixed oxide method. The synthesized powders were characterized by powder X-ray diffraction (XRD) and scanning electron microscope (SEM). The thermal, magnetic and dielectric properties have been discussed.

\section{Experimental procedure}

Mixed oxide method was used to obtain $\mathrm{Ni}_{0.284} \mathrm{Zn}_{0.549} \mathrm{Cu}_{0.183} \mathrm{Fe}_{1.984} \mathrm{O}_{4}$ PMT. The weight of each constituent is measured to match the requirement 
of mole fraction in the piezomagnetic material. Oxide powders $(\mathrm{NiO}-8.9 \%, \mathrm{ZnO}-18.7 \%, \mathrm{CuO}-6.1 \%$ and $\left.\mathrm{Fe}_{2} \mathrm{O}_{3}-66.3 \%\right)$ with high purity were used as raw materials. The mixture of starting raw materials was homogenized and ground in a ball mill for $48 \mathrm{~h}$ in order to reduce particle size. After milling the mixtures were calcined in a high density alumina crucible at approximately $900^{\circ} \mathrm{C}$ to increase the evaporation rate of the solvent. A typical sintering schedule at a heating rate of $20^{\circ} \mathrm{C} / \mathrm{min}$ for $120 \mathrm{~min}$ with a final temperature and pressure of $1100^{\circ} \mathrm{C}$ and $50 \mathrm{MPa}$, respectively (to release the organic binder) is applied to obtain the green composite of piezomagnetic material (pellet size is $15 \mathrm{~mm}$ diameter and thickness $1.36 \mathrm{~mm}$ ). The preparation of $\mathrm{Ni}_{0.284} \mathrm{Zn}_{0.549} \mathrm{Cu}_{0.183} \mathrm{Fe}_{1.984} \mathrm{O}_{4}$ PMT is shown in Fig. 1 as a flow chart.

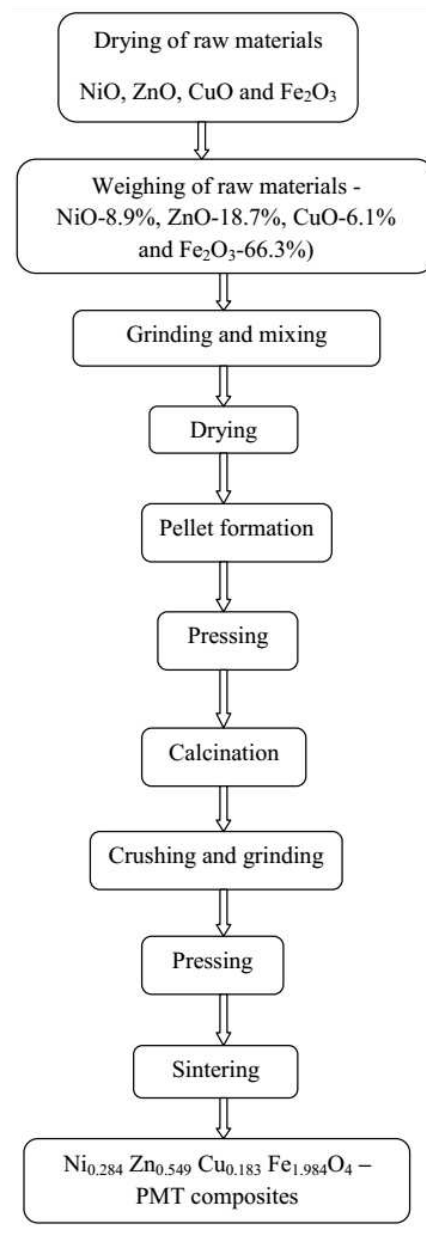

Fig. 1. Flow chart for synthesis of $\mathrm{Ni}_{0.284} \mathrm{Zn}_{0.549} \mathrm{Cu}_{0.183} \mathrm{Fe}_{1.984} \mathrm{O}_{4}$ PMT.

\section{Characterization}

Rich Seifert X-ray powder diffractometer with $\mathrm{Cu} K_{\alpha}$ radiation $(\lambda=1.5406 \AA)$ in the $2 \theta$ range from 10 to $70^{\circ}$ at a scanning rate of $1 \mathrm{~min}^{-1}$ is used to collect the X-ray powder diffraction data at room temperature. The morphology and microstructure of as-prepared
$\mathrm{Ni}_{0.284} \mathrm{Zn}_{0.549} \mathrm{Cu}_{0.183} \mathrm{Fe}_{1.984} \mathrm{O}_{4}$ PMT composites was observed by a scanning electron microscope. The samples used for SEM observation were polished down to optical quality. Before the SEM observation, a layer of gold (about $20 \mathrm{~nm}$ ) was deposited on the etched surface by sputtering to avoid the electron accumulation on the sample surface. A JEOL JSM 6460 LV scanning electron microscope was used to conduct the observations. The thermal stability and complete formation of the synthesized compound is investigated by thermogravimetric analysis (TGA) and differential temperature analysis (DTA). The thermal behavior was studied at $20^{\circ} \mathrm{C} \mathrm{min}{ }^{-1}$ by using a SDT Q 600 V 8.2 Built 95 thermal analyzer. The experimental conditions were: (a) continuous heating from room temperature to $800^{\circ} \mathrm{C}$ for $20^{\circ} \mathrm{C} \mathrm{min}^{-1}$; (b) nitrogen gas dynamic atmosphere $\left(90 \mathrm{~cm}^{3} \mathrm{~min}^{-1}\right)$; (c) alumina, crucible; (d) sample of mass: $3.6120 \mathrm{mg}$ for $20^{\circ} \mathrm{C} \mathrm{min}{ }^{-1}$. The prepared $\mathrm{Ni}_{0.284} \mathrm{Zn}_{0.549} \mathrm{Cu}_{0.183} \mathrm{Fe}_{1.984} \mathrm{O}_{4}$ PMT was subjected to dielectric studies using a HIOKI model 353250 LCR HITESTER with a conventional two-terminal sample holder. The sample was electrode on either side with air-drying silver paste so that it behaves like a parallel capacitor. The studies were carried out from $100^{\circ} \mathrm{C}$ to $400^{\circ} \mathrm{C}$ for frequency varying from $50 \mathrm{~Hz}$ to $5 \mathrm{MHz}$. Magnetic measurements were carried out on vibrating sample magnetometer (Lakeshore VSM 7410) at room temperature.

\section{Results and discussion}

\subsection{Structural analysis}

X-ray powder diffraction analysis is used to check the crystalline purity of synthesized $\mathrm{Ni}_{0.284} \mathrm{Zn}_{0.549} \mathrm{Cu}_{0.183} \mathrm{Fe}_{1.984} \mathrm{O}_{4} \quad$ PMT. Figure 2 shows the powder X-ray diffraction of synthesized $\mathrm{Ni}_{0.284} \mathrm{Zn}_{0.549} \mathrm{Cu}_{0.183} \mathrm{Fe}_{1.984} \mathrm{O}_{4}$ PMT. The XRD pattern

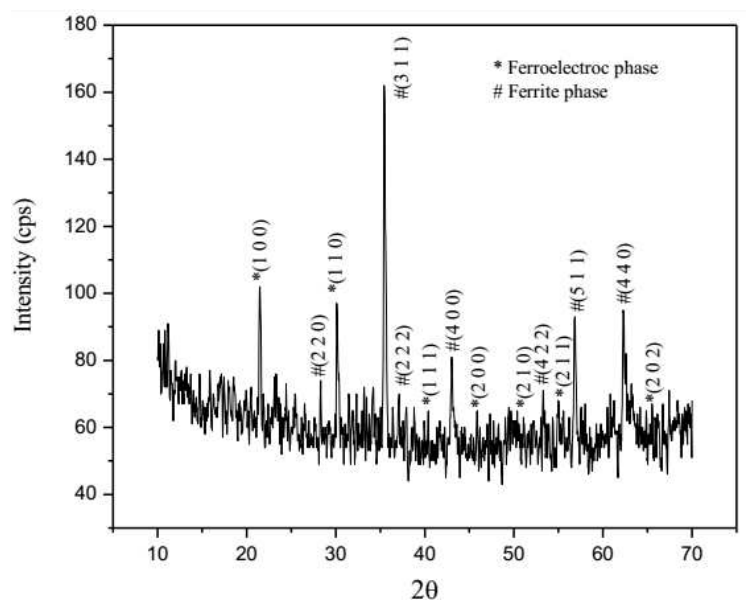

Fig. 2. X-ray powder diffraction pattern of $\mathrm{Ni}_{0.284} \mathrm{Zn}_{0.549} \mathrm{Cu}_{0.183} \mathrm{Fe}_{1.984} \mathrm{O}_{4}$ PMT.

reveals the presence of ferrite and ferroelectric phase of the synthesized compound and crystallizes in the simple cubic system with the lattice constant $a=7.7693 \AA$. 
All the prominent peaks are indexed which indicates the absence of impurities or intermediate phases in the composite [17]. The studies on crystalline materials require an accurate determination of crystallite size as well as the microstrain induced in the material. XRD is a well known technique for this purpose. Based on XRD principles, numerous approaches such as the use of the Scherrer equation, integral breadth analysis, single line approximation, the Hall-Williamson method, the Rietveld refinement method etc. have been developed for the crystallite size determination. The crystallite size $(D)$ of $\mathrm{Ni}_{0.284} \mathrm{Zn}_{0.549} \mathrm{Cu}_{0.183} \mathrm{Fe}_{1.984} \mathrm{O}_{4}$ PMT was determined by Debye-Scherrer's formula using equation

$$
D=K \lambda /\left(\beta_{1 / 2} \cos \theta\right),
$$

where $K=0.89 ; \lambda=1.5405 \AA$ and $\beta_{1 / 2}$ is the peak width of the reflection at half intensity. The maximum intensity peak occurs at $2 \theta=162^{\circ}$. As the powder sample was used for XRD, the effects of the strain, instruments and other unknown factor causing the broadening of the peak were ignored. The average value of the crystallite size of $\mathrm{Ni}_{0.284} \mathrm{Zn}_{0.549} \mathrm{Cu}_{0.183} \mathrm{Fe}_{1.984} \mathrm{O}_{4}$ PMT is found to be $19.332 \mu \mathrm{m}$.

\subsection{Surface morphology}

Figure 3 shows the typical SEM image of the $\mathrm{Ni}_{0.284} \mathrm{Zn}_{0.549} \mathrm{Cu}_{0.183} \mathrm{Fe}_{1.984} \mathrm{O}_{4}$ PMT. From SEM analysis, the primary particle size of the powder has been determined and it is found to be in the range of $1 \mu \mathrm{m}-$ $500 \mathrm{~nm}$. The distribution of the particle size of the pellet is not uniform, and it may be due to agglomeration of particles that resulted during the preparation of pellet. It is observed that the samples are uniform and the grains are in the order of $\mu \mathrm{m}$. It can be noticed that the samples are uniform and the grains are in order of $\mu \mathrm{m}$ size. These micrographs revealed that the grain structure of the samples is dense, crack free, and smooth [18, 19].

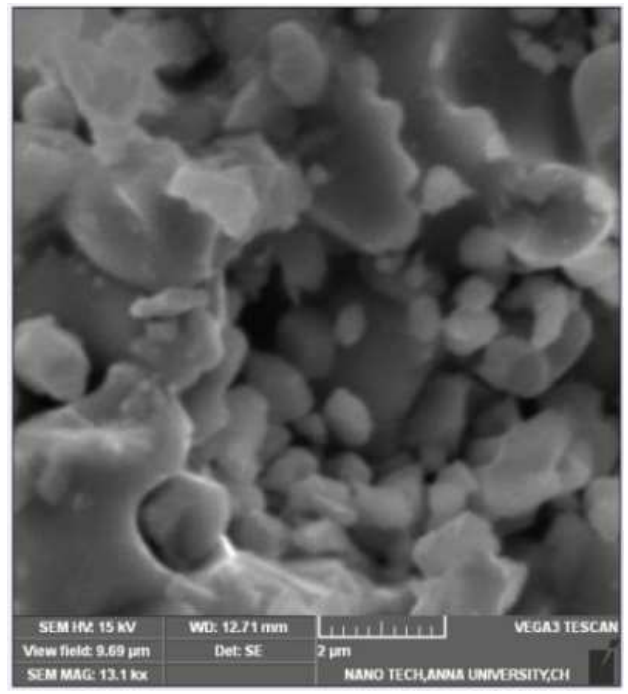

Fig. 3. SEM images of $\mathrm{Ni}_{0.284} \mathrm{Zn}_{0.549} \mathrm{Cu}_{0.183} \mathrm{Fe}_{1.984} \mathrm{O}_{4}$ PMT.

\subsection{Thermal analysis}

TG-DTG curve of $\mathrm{Ni}_{0.284} \mathrm{Zn}_{0.549} \mathrm{Cu}_{0.183} \mathrm{Fe}_{1.984} \mathrm{O}_{4}$ PMT is shown in Fig. 4. Two main stages in the decomposition reactions were shown in the TGA curve. Exothermic and endothermic reactions which relate to solvent removal and crystallization of $\mathrm{Ni}_{0.284} \mathrm{Zn}_{0.549} \mathrm{Cu}_{0.183} \mathrm{Fe}_{1.984} \mathrm{O}_{4}$ PMT are shown in TGDTG curve. The first stage of decomposition starts at $331.52{ }^{\circ} \mathrm{C}$ and ends at $383.22^{\circ} \mathrm{C}$ with a weight loss of $21.07 \%$. The corresponding exothermic peak is seen at $370.97^{\circ} \mathrm{C}$. This shows that the synthesized $\mathrm{Ni}_{0.284} \mathrm{Zn}_{0.549} \mathrm{Cu}_{0.183} \mathrm{Fe}_{1.984} \mathrm{O}_{4}$ PMT is thermally stable up to $370^{\circ} \mathrm{C}$. The second stage of decomposition starts at $512.82^{\circ} \mathrm{C}$ and ends at $570.60^{\circ} \mathrm{C}$ with a weight loss of $3.049 \%$. The corresponding exothermic peak is seen at $540.01^{\circ} \mathrm{C}$. In DTG curve, an endothermic peak is seen at $186.15^{\circ} \mathrm{C}$ and is due to the water loss from the compound. After that, there was a slight weight loss due to the residual organic groups and carbon compositions.

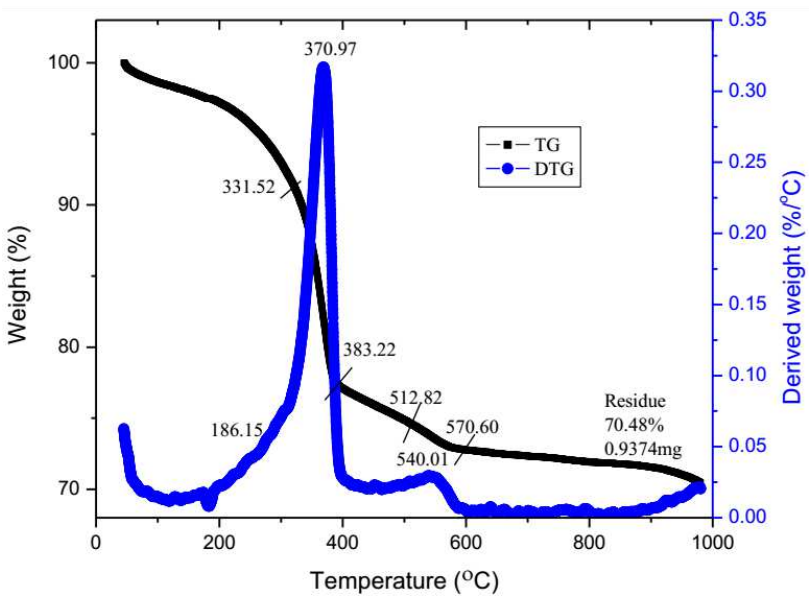

Fig. 4. TG-DTG

$\mathrm{Ni}_{0.284} \mathrm{Zn}_{0.549} \mathrm{Cu}_{0.183} \mathrm{Fe}_{1.984} \mathrm{O}_{4}$ PMT.

of

Mass conversion can be calculated as

$\alpha=\left(m_{0}-m\right) /\left(m_{0}-m_{\mathrm{f}}\right)$,

where $m_{0}$ is the initial mass, $m$ is the corresponding mass, $m_{\mathrm{f}}$ is the final mass.

Kinetic studies assumed that the isothermal rate of conversion, $\mathrm{d} \alpha / \mathrm{d} t$, is a linear function of reactant concentration loss and of temperature independent function of the conversion $\alpha$,

$$
\mathrm{d} \alpha / \mathrm{d} t=k f(\alpha)
$$

where $f(\alpha)$ is reaction model that depends on the mechanism of degradation. The function $k$ is described by the Arrhenius expression

$$
\begin{aligned}
& k=A \exp \left(-E_{\mathrm{a}} / R T\right), \\
& \ln k=\ln A-E_{\mathrm{a}} / R T,
\end{aligned}
$$

where $A$ is pre-exponential factor independent of temperature, $E_{\mathrm{a}}$ is activation energy, $R$ is the universal gas constant. 
The linear Arrhenius plot of $\ln k$ versus $1 / T$ is plotted from the TG data. From the slope $\left(-E_{\mathrm{a}} / R\right)$, the activation energy $\left(E_{\mathrm{a}}\right)$ was calculated.

Equations (2) and (3) put together give

$$
\mathrm{d} \alpha / \mathrm{d} t=\beta(\mathrm{d} \alpha / \mathrm{d} T)=A f(\alpha) \exp \left(-E_{\mathrm{a}} / R T\right),
$$

where $\beta$ is the heating rate $\left(20^{\circ} \mathrm{C} / \mathrm{min}\right), f(\alpha)$ is the reaction model.

\subsection{Broido method}

In Broido's approximation [20]:

$$
\ln (\ln (1 / \alpha))=\left(-E_{\mathrm{a}} / R T\right)+\left[R A T^{2} / E_{\mathrm{a}} \beta\right],
$$

the thermal degradation is considered as first order and the calculations are done accordingly. The value of the activation energy $\left(E_{\mathrm{a}}\right)$ can be calculated from the slope of the plot of graph between $\ln (\ln (1 / \alpha))$ and $1 / T$ (Fig. 5A). The calculated activation energy is found to be $249.98 \mathrm{~kJ} \mathrm{~mol}^{-1}$ with standard deviation and $R$ value of 0.2574 and 0.93326 , respectively.
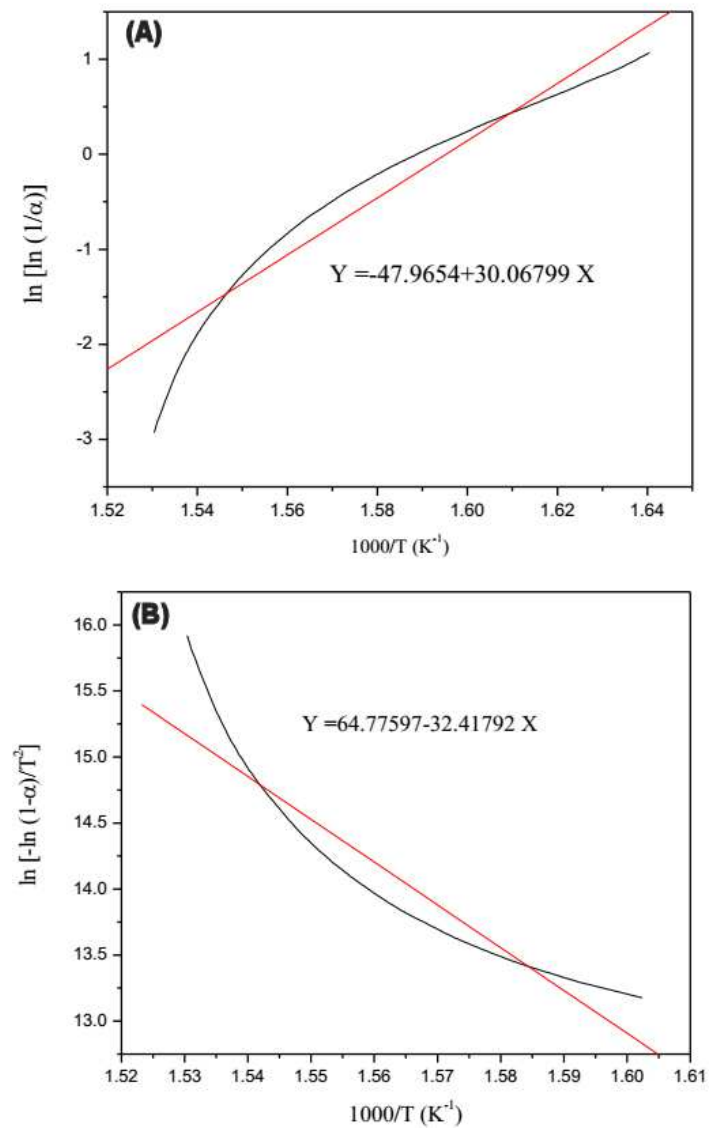

Fig. 5. (A) Broido's method, (B) Coats-Redfern method.

\subsection{Coats-Redfern method}

By using the Coats-Redfern expression [21]:

$$
\begin{aligned}
\ln \left(-\ln (1-\alpha) / T^{2}\right) & =\ln \left(A R / \beta E_{\mathrm{a}}\right)\left[1-2 R T / E_{\mathrm{a}}\right] \\
-E_{\mathrm{a}} / R T \text { for } n & =1,
\end{aligned}
$$

the value of the activation energy $\left(E_{\mathrm{a}}\right)$ can be calculated from the slope of the plot of graph between $\ln \left(-\ln (1-\alpha) / T^{2}\right)$ and $1 / T$ (Fig. 5B). The calculated activation energy is calculated to be $269.52 \mathrm{~kJ} \mathrm{~mol}^{-1}$ with standard deviation and $R$ value of 0.22709 and 0.90004 , respectively.

It is found that the activation energy calculated by the Coats-Redfern method (269.52 $\left.\mathrm{kJ} \mathrm{mol}^{-1}\right)$ is found to be higher than Broido's method $\left(249.98 \mathrm{~kJ} \mathrm{~mol}^{-1}\right)$. This may be due to the degradation mechanism i.e. the temperature of phase transition and this may also be due to the kinetics of degradation of the $\mathrm{Ni}_{0.284} \mathrm{Zn}_{0.549} \mathrm{Cu}_{0.183} \mathrm{Fe}_{1.984} \mathrm{O}_{4}$ PMT under investigation.

\subsection{Magnetic studies}

Piezomagnetic materials are subset of ferromagnetic materials which have a number of characteristics features arising from the coupling between the local magnetic moments and the lattice. In an applied magnetic field they undergo a dimensional change. The inverse of magnetostriction is that the application of the mechanical strain may change the state of magnetization within the sample usually seen as change in permeability. Room temperature magnetic properties of $\mathrm{Ni}_{0.284} \mathrm{Zn}_{0.549} \mathrm{Cu}_{0.183} \mathrm{Fe}_{1.984} \mathrm{O}_{4}$ PMT were investigated using a vibrating sample magnetometer. If a material is placed within a uniform magnetic field $H$, a magnetic moment $m$ will be induced in the sample. In a VSM, a sample is placed within suitably placed sensing coils, and is made to undergo sinusoidal motion, i.e., mechanically vibrated. The resulting magnetic flux changes induce

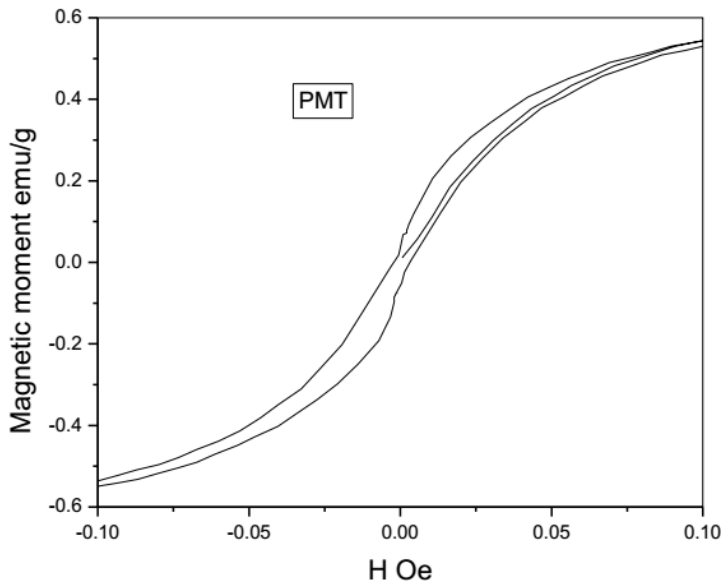

Fig. 6. Magnetization hysteresis $(M-H)$ curve of $\mathrm{Ni}_{0.284} \mathrm{Zn}_{0.549} \mathrm{Cu}_{0.183} \mathrm{Fe}_{1.984} \mathrm{O}_{4}$ PMT.

a voltage in the sensing coils that is proportional to the magnetic moment of the sample. Figure 6 shows the magnetization versus applied magnetic field $(M-H)$ curves of $\mathrm{Ni}_{0.284} \mathrm{Zn}_{0.549} \mathrm{Cu}_{0.183} \mathrm{Fe}_{1.984} \mathrm{O}_{4}$ PMT. As expected, very feeble ferromagnetic properties were observed at room temperature in the low field region. 


\subsection{Dielectric studies}

Figure 7A presents the variation of electrical permittivity measured at different frequencies ranges from $50 \mathrm{~Hz}$ to $5 \mathrm{MHz}$ for four different temperatures viz. 100, 200, 300 and $400^{\circ} \mathrm{C}$. It is found that electrical permittivity initially decreases with increase in frequency and attains a near zero or even less value at higher frequencies. Also, it shows an increase tendency of all the electrical permittivity at higher frequencies. This type of behaviour may be attributed to the enhancement of grain size, compactness and the structural quality of the material [22-24]. At lower frequencies, dispersion is large which suggests that there is a prominent contribution of space charge polarization also at the electric polarization process. As the frequency increases, ionic and orientation polarization decreases and finally disappears due to the inertia of the molecules and ions. The studied $\mathrm{Ni}_{0.284} \mathrm{Zn}_{0.549} \mathrm{Cu}_{0.183} \mathrm{Fe}_{1.984} \mathrm{O}_{4}$ PMT reveal dispersion due to the Maxwell-Wagner type interfacial polarization in agreement with Koop's phenomenological theory $[25,26]$.
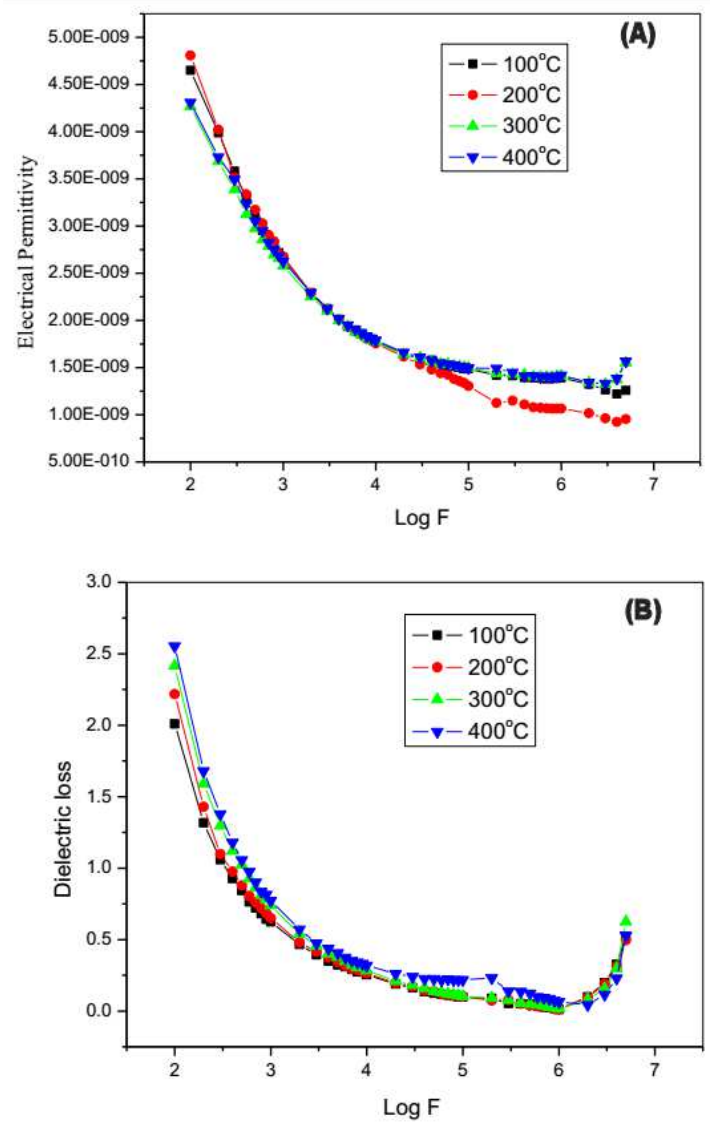

Fig. 7. (A) Variation of electrical permittivity vs. $\log F,(\mathrm{~B})$ variation of dielectric $\operatorname{loss}$ vs. $\log F$.

In general, electrical permittivity slowly increases with temperature, reaches a maximum value $\left(\varepsilon_{\max }\right)$, and then it decreases. It is also observed that the electrical
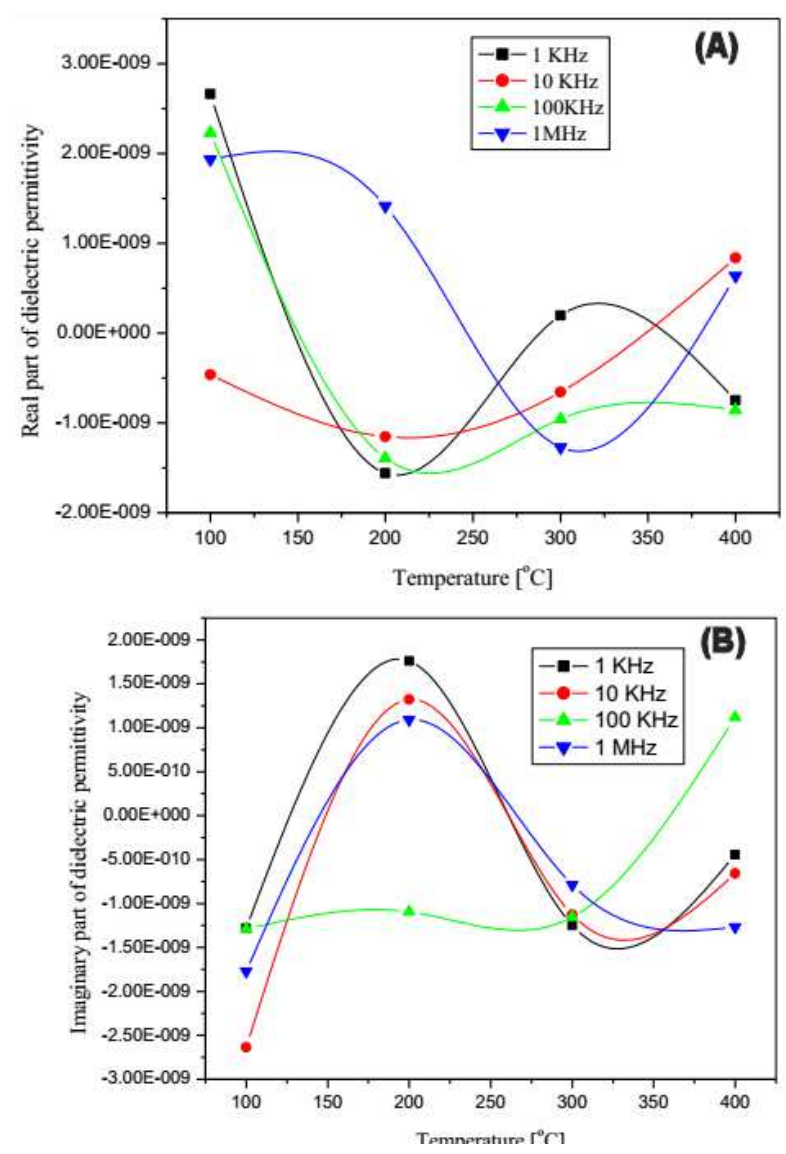

Fig. 8. (A) Real part of dielectric permittivity vs. temperature at different frequencies, (B) imaginary part of dielectric permittivity vs. temperature at different frequencies.

permittivity decreases with increase in frequency and a broad peak is observed. The broad nature of peaks indicates diffuse phase transition [27]. The dielectric loss also decreases with increase in frequencies and small hump is seen at higher frequencies indicating the phase transition. When the temperature is increased the orientation of the dipole is facilitated and thus increases the orientational polarization which leads to increases of electrical permittivity with temperature. However, after a certain temperature the thermal energy is very high to restrict the polarization which leads to the disordered state (paraelectric). Hence, we have observed a transition from ferroelectric to paraelectric phase with the temperature. The variation of real and imaginary part of dielectric permittivity at temperatures 100, 200, 300, and $400^{\circ} \mathrm{C}$ for different frequencies $1,10,100 \mathrm{kHz}$, and $1 \mathrm{MHz}$ frequencies is shown in Fig. 8A,B, respectively. It was observed that tangent loss is constant up to $200^{\circ} \mathrm{C}$ and then increases to a maximum value due to space charge polarization and again decreases with increasing temperature [28-30].

Figures 9 and 10 give the variation in resistivity and conductivity with the frequency for 


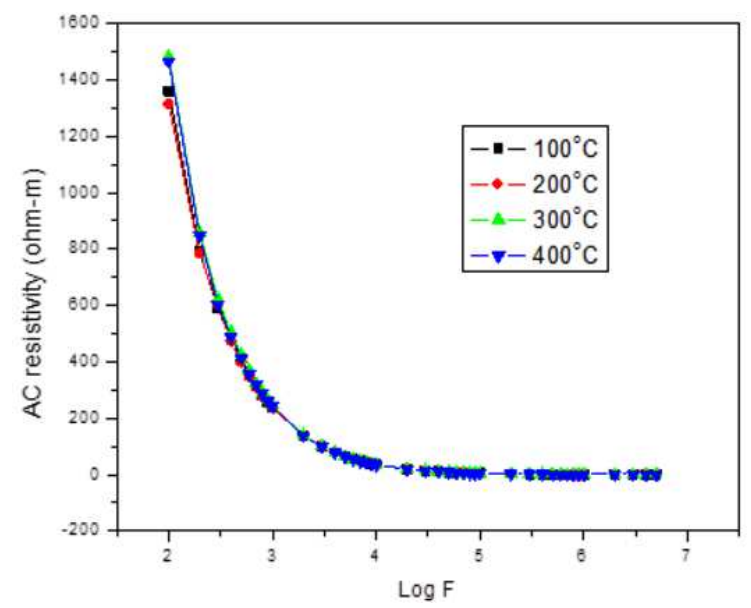

Fig. 9. ac resistivity vs. $\log F$.

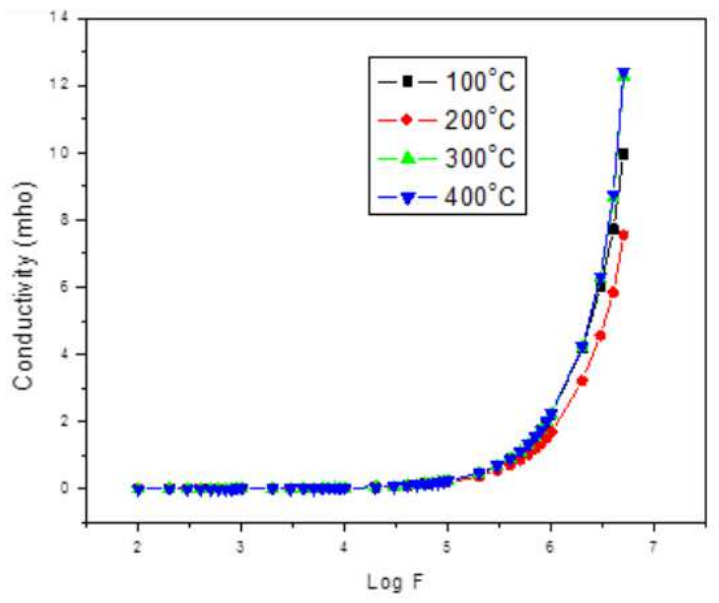

Fig. 10. Conductivity vs. $\log F$.

$\mathrm{Ni}_{0.284} \mathrm{Zn}_{0.549} \mathrm{Cu}_{0.183} \mathrm{Fe}_{1.984} \mathrm{O}_{4}$ PMT. The ac resistivity and ac conductivity were calculated using the following relation:

$$
\begin{aligned}
& \rho=\frac{A}{2 \pi f C d}, \\
& \sigma=\frac{1}{\rho},
\end{aligned}
$$

where $C$ is the capacitance, $d$ is the thickness, $A$ is the area of the crystal, and $f$ is the frequency of the applied field.

It is seen in Fig. 9 that ac resistivity decreased rapidly as frequency increased. Obviously reverse trend was observed for ac conductivity (Fig. 10) [31].

\section{Conclusion}

In the present work, we have prepared piezomagnetic material of composition $\left(\mathrm{Ni}_{0.284} \mathrm{Zn}_{0.549} \mathrm{Cu}_{0.183} \mathrm{Fe}_{1.984}\right)$ by mixed oxide method. $\mathrm{Ni}_{0.284} \mathrm{Zn}_{0.549} \mathrm{Cu}_{0.183} \mathrm{Fe}_{1.984} \mathrm{O}_{4}$ PMT crystallizes in the simple cubic system with the lattice constant $a=7.7693 \AA$. X-ray diffraction pattern reveals the presence of ferrite and ferroelectric phase of the synthesized compound. The average grain size of $\mathrm{Ni}_{0.284} \mathrm{Zn}_{0.549} \mathrm{Cu}_{0.183} \mathrm{Fe}_{1.984} \mathrm{O}_{4}$ PMT material is found to be $19.332 \mu \mathrm{m}$. From SEM analysis, the primary particle size of the powder has been determined and it is found to be in the range of $1 \mu \mathrm{m}-500 \mathrm{~nm}$. Thermal studies show that the synthesized $\mathrm{Ni}_{0.284} \mathrm{Zn}_{0.549} \mathrm{Cu}_{0.183} \mathrm{Fe}_{1.984} \mathrm{O}_{4}$ PMT material is thermally stable up to $370.97^{\circ} \mathrm{C}$. The activation energy calculated by the Coats-Redfern method $\left(269.52 \mathrm{~kJ} \mathrm{~mol}^{-1}\right)$ is found to be higher than Broido's method (249.98 kJ mol $\left.{ }^{-1}\right)$. Vibration sample magnetometer studies confirm the ferromagnetic nature of the studied material at room temperature in the low field region. Dielectric measurement demonstrates the decrease in electrical permittivity with increase in temperature. The variation of electrical permittivity with temperature shows a sharp peak at $200^{\circ} \mathrm{C}$ which indicates the phase transition.

\section{References}

[1] J.H. Huang, W.S. Kuo, J. Appl. Phys. 81, 4889 (1997).

[2] J.H. Huang, J. Appl. Phys. 78, 6491 (1995).

[3] J.H. Huang, W.S. Kuo, Acta Metall. Mater. 44, 4889 (1997).

[4] A. Ballato, IEEE Trans. Ultrason. Ferroelectr. Freq. Contr. 48, 1180 (2001)

[5] F.E. Crawley, J. De Luis, Am. Inst. Aeronautics Astronautics 25, 1373 (1987).

[6] K.B. Nathaway, A.E. Clark, MRS Bull. 18, 34 (1993).

[7] Quanlu Li, Yuan Li, Zhaohui Huang, "Multifunctional Piezomagnetic Ferrite Materials and Their Newly Acoustical and Vibration Control Devices", PIERS Proc., Hangzhou, China 2008.

[8] Quanlu Li, Yuan Li, Zhaohui Huang, in: Progress in Electromagnetics Research Symp., Beijing (China), 2009.

[9] C.W. Nan, J. Appl. Phys. 82, 5268 (1997).

[10] Qun Guan, Commun. Control Sci. Eng. 1, 1 (2013).

[11] T. He, Q. Huang, A.P. Ramirez, Y. Wang, K.A. Regan, N. Rogado, M.A. Hayward, M.K. Haas, J.S. Slusky, K. Inumara, H.W. Zandbergen, N.P. Ong, R.J. Cava, Nature (London) 411, 54 (2001).

[12] K. Kamishima, T. Goto, H. Nakagawa, N. Miura, M. Ohashi, N. Mori, T. Sasaki, T. Kanomata, Phys. Rev. B 63, 024426 (2000).

[13] P. Lukashev, F.R. Sabirianov, K. Belashchenko, Phys. Rev. B 78, 184414 (2008).

[14] Y. Shen, J. Gao, Y. Wang, P. Finkel, J. Li, D. Viehland, Appl. Phys. Lett. 102, 172904 (2013).

[15] S. Balu, G.R. Kannan, K. Rajalingam, Int. J. Eng. Sci. Res. Technol. 3, 678 (2014).

[16] D.A. Hadjiloizi, A.V. Georgiades, A.L. Kalamkarov, S. Jothi, Europ. J. Mech. A/Solids 39, 298 (2013).

[17] S.S. Sawant, P.K. Gaikwad, JAAST Mater. Sci. 1, 26 (2014). 
[18] H.-K. Liu, J.H. Huang, J. Mater. Sci. 40, 1975 (2005).

[19] D. Viehland, S.J. Jang, L.E. Cross, M. Wuttig, Phys. Rev. B 46, 8003 (1992).

[20] A. Broido, J. Polym. Sci. 7, 1761 (1969).

[21] A.W. Coats, J.P. Redfern, Nature 201, 68 (1964).

[22] T.P. Rao, M.C.S. Kumar, Appl. Surf. Sci. 255 4579 (2009).

[23] H. Li, J. Wang, H. Liu, H. Zhang, X. Li, J. Cryst. Growth 275, 943 (2005).

[24] J.W. Zhai, L.Y. Zhang, X. Yao, Ceram. Int. 26, 883 (2000).

[25] C.G. Koops, Phys. Rev. 83, 121 (1951).

[26] M. Venkata Ramana, N. Ramamanohar Reddy, B.S. Murty, V.R.K. Murthy, K.V. Siva Kumar, Adv. Condens. Matter Phys. 010, 763406 (2010).
[27] K.K. Patankar, V.L. Mathe, R.P. Mahajan, S.A. Patil, R.M. Reddy, K.V. Siva Kumar, Mater. Chem. Phys. 72, 23 (2001).

[28] M.E. Lines, A.M. Glass, Principles and Applications of Ferroelectrics and Related Materials, Oxford Univ. Press, Oxford 1977.

[29] R. Rajan, R. Kumar, B. Behera, R.N.P. Choudhary, Mater. Chem. Phys. 115, 473 (2009).

[30] N. Kanagathara, G. Anbalagan, Int. J. Opt. 2012 826763 (2012).

[31] N. Pattanaboonmee, P. Ramasamy, R. Yimnirun, P. Manyum, J. Cryst. Growth 314, 1417 (2010). 